\title{
Analysis of urban growth at Cairo, Egypt using remote sensing and GIS
}

\author{
Mohamed E. Hereher
}

Department of Environmental Sciences, Faculty of Science at Damietta, Mansoura University, Mansoura, Egypt; mhereher@gmail.com

Received 21 January 2012; revised 22 February 2012; accepted 11 March 2012

\begin{abstract}
The main objective of the present study was to highlight and analyze the exchange between the land cover components at Cairo with focusing on urban area and agricultural land between 1973 and 2006 using Landsat satellite data with the aid of Digital Elevation Models (DEM). The techniques utilized in this investigation involved a rigorous supervised classification of the Landsat and the DEM images. Results showed that urban area of Cairo was $233.78 \mathrm{~km}^{2}$ in 1973 and increased to $557.87 \mathrm{~km}^{2}$ in 2006 . The cut-off from agricultural lands was $136.75 \mathrm{~km}^{2}$, whereas urbanization into the neighboring desert was estimated at $187.32 \mathrm{~km}^{2}$ for the same period. The direction of urban sprawl was mainly controlled by regional topography. Urban sprawl was attributed mainly to accelerated population growth.
\end{abstract}

Keywords: Cairo; Urban Sprawl; Landsat

\section{INTRODUCTION}

Satellite remote sensing has been considered an ideal technology and data source for large-area land cover classifications and change detection [1]. Remote sensing has witnessed several improvements in the spatial, spectral, temporal resolutions and the possibility for stereoimaging. For example, the first generation of the Landsat satellite (Multi-Spectral Scanner, MSS) provided images with $80 \mathrm{~m}$ spatial resolution and 4 spectral bands. Later, the Landsat Thematic Mapper (TM) and the Enhanced Thematic Matter plus (ETM+) afforded images with 30 $\mathrm{m}$ spatial resolution and 7 basic spectral bands in the visible, near infrared, shortwave infrared and thermal infrared. However, other satellite sensors could provide images with finer spatial resolution and a greater number of spectral bands. Stereo-imaging has emerged as the result of obtaining an image of a given area using two sensors mounted at a distance on the same satellite and work simultaneously. Most of DEMs have been provided by the Shuttle Radar Topography Mission (SRTM) onboard the Space Shuttle Endeavor in its journey during Dec. 2000. DEM images are available in 30, 90 and 1000 $\mathrm{m}$ spatial resolutions. The $30 \mathrm{~m}$ resolution DEMs are available only to the United States, whereas the $90 \mathrm{~m}$ and $1000 \mathrm{~m}$ resolution are available to the entire world and could be accessed from the United States Geological Survey (USGS) online open resources.

In Egypt, remote sensing and its applications have emerged as early as this technology was invented. Early studies were based on visual interpretation of MSS data to map sand accumulations in the Western Desert [2]. During 1980s, soil salinization was a good target to monitor in satellite images [3]. Advanced image processing was observed in the literature during 1990s as many specialists applied image classification, principal component analysis and digital change detection [4-6]. Advanced techniques for mapping land cover change detection, such as vegetation indices and water indices were applied in research since late 1990 until now [7,8]. Analysis of regional DEM is very recent topographic application of remote sensing in Egypt [9].

Mapping expansion of urban areas is one of the most important and successful applications of remote sensing. As urban areas are expanding quickly, routine surveying is not accurate, time and labor consuming, expensive and tedious. On the other hand, satellite remote sensing could deliver periodic, large coverage, less expensive and accurate mapping. These advantages encouraged using remote sensing over many regions in the world. Urbanization dynamics at Washington DC metropolitan area was studied using Landsat MSS and TM images between 1973 and 1996 [10]. Aerial photographs and TM images assisted with finer resolution IKONOS images were operated to map urban growth and direction of Al-Ain City, UAE between 1976 and 2000 [11]. Urbanization change was carried out for Minnesota, USA metropolitan area using TM images acquired between 1986 and 2002 [12]. In Egypt, SPOT images acquired between 1987 and 1995 were utilized to map urbanization at the cities of Tanta and El-Mahala Al-Kobra [13]. In addition, the total built up area of the Greater Cairo was determined using 
Landsat TM (1986) and ETM+ (1999) [14] and revealed a net increase of urban areas from $344.4 \mathrm{~km}^{2}$ in 1986 to $460.4 \mathrm{~km}^{2}$ in 1999 with a total expansion area of $116 \mathrm{~km}^{2}$ in 13 years. The main objective of the present study is to operate remote sensing using old and most available and recent images in order to map landscape change in Cairo between 1973 and 2006 with focusing on urbanization and agricultural land loss. Analyzing the direction and driving forces of urban sprawl are other objectives of this study.

\section{THE STUDY AREA}

Cairo, the capital of Egypt, is one of the most crowded cities in Egypt (Figure 1) and is considered a world mega-city. Mapping urban sprawl is important to understand and analyze the relationships between the geomorphology (highlands and deserts), natural resources (agricultural lands and the Nile River) and human activates. Agricultural lands around Cairo have witnessed severe encroachment practices due to the accelerated population growth. However, adjacent desert plains have also witnessed urbanization practices to encompass the intensive population growth. Population of Cairo (Cairo city and Giza) increased from about 7 millions in 1976 [15] to about 14 million in 2006 (the Egyptian Central Agency for Public Mobilization and Statistics). The im- portance of Cairo arises from its location in the mid-way between the Nile Valley and the delta. Main government facilities and services occur at Cairo. Major settlement sectors in Cairo include: Cairo center, Giza, Shubra ElKhima, El-Maadi, Helwan, Nasr City, and the new cities of El-Obour, El-Salam and New Cairo.

\section{METHODS}

\subsection{Satellite Data}

To accomplish the objectives of the present study, three available satellite images were obtained from the United States Geological Survey (USGS) databases online resources: Two cloud-free Landsat MSS and ETM+ images acquired in May 1973 and August 2006, respectively and one SRTM DEM (90 m spatial resolution) acquired in December 2000. Although there were a plenty of satellite images covering the study period, it was important to utilized images covering the summer season to ensure that agricultural land encompassing Cairo are fully cultivated, and to have images with the sun elevation angle most closer to nadir. All the images were originally georeferenced to the Universal Transverse Mercator (UTM, zone $36^{\circ} \mathrm{N}$ ). Atmospheric correction was applied to remove the dust and haze effect from each image by using the dark-object subtraction method

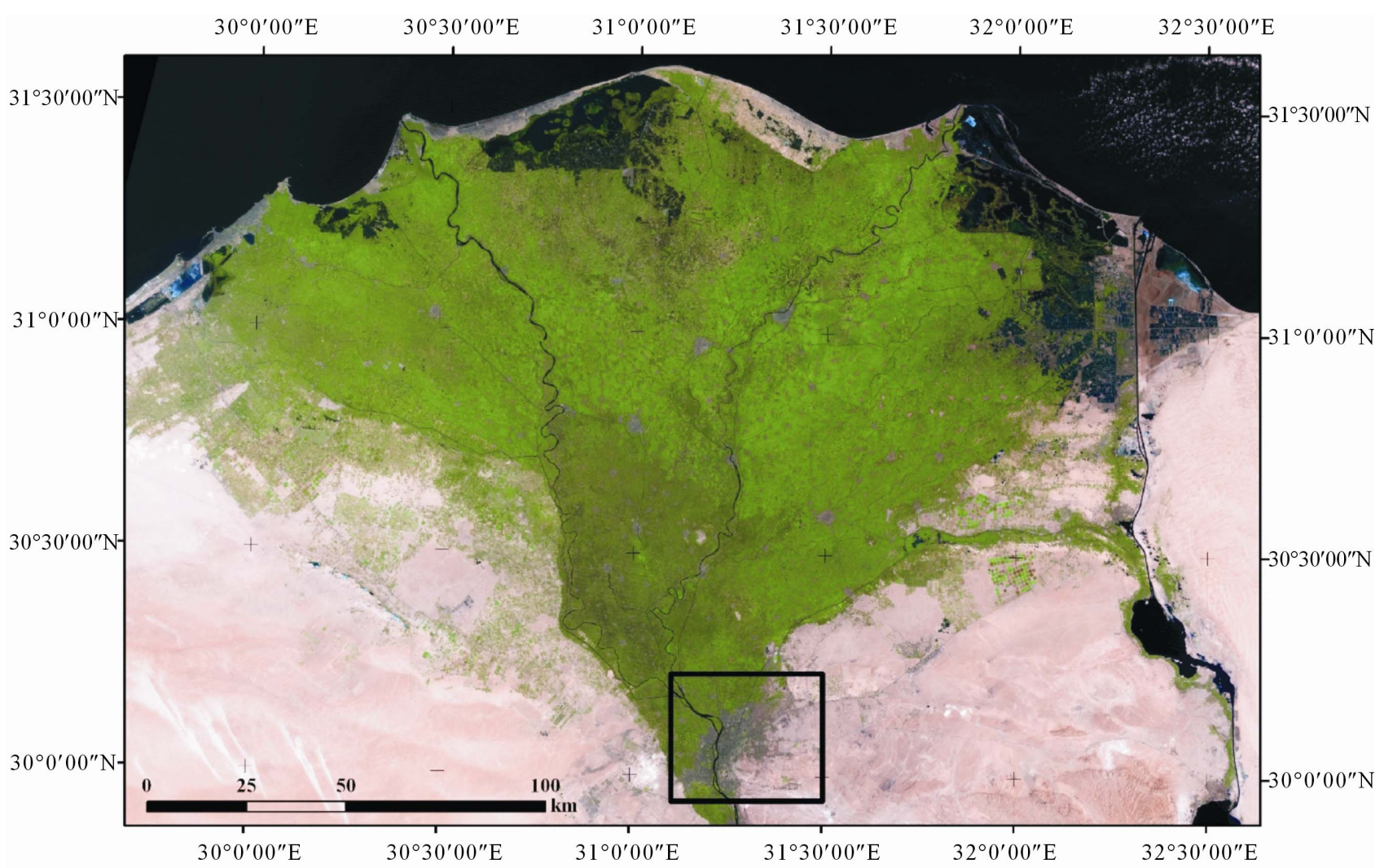

Figure 1. A satellite TM mosaic image of the Nile Delta showing the location of Cairo. 
[16] (Chavez, 1996). A subset image (Figure 2) was created from each MSS and ETM+ image for subsequent classification.

\subsection{Image Classification and Accuracy Assessment}

The supervised classification was applied using ERDAS Imagine for the classification process. At least 100 training sites (signatures) were chosen to represent land cover classes, such as agricultural land, urban, water (the Nile) and desert. The maximum likelihood classifier (MLC) was the algorithm applied for the clustering process. The four spectral bands in the MSS image and the six bands in the ETM+ image (the thermal band was excluded) were incorporated in the classification process. After classification, a major $3 \times 3$ filter was applied to remove anomalous pixels from the matrix. All pixels pertaining to each class were recoded together and the gross area of this class was counted. With the help of the final version of the Google Earth, the ETM+ classified image of 2006 was visually compared with the true color and finer spatial resolution image of Cairo as appeared in the Google Earth, which was acquired approximately at the same acquisition date of the ETM+ image. In addition, 100 random points were selected at each classified MSS and ETM+ image on a stratified random approach and compared digitally with the corresponding pixels of the original MSS and ETM+ images as a reference data. If reference pixels are selected randomly, the possibility of bias is lowered and classification accuracy rises [17]. The producer and user accuracies as well as kappa statistics were obtained for each land cover map. The DEM was classified in ArcGIS to highlight the regional topography of Cairo. The River Nile course was digitized and superimposed the classified DEM to display the occurrence and relative distances of highlands.

\subsection{Change Detection}

There are various methods of addressing change detection using satellite images [18]. The post-classification change detection approach is one of the most common, accurate and quantitative techniques [19]. The purpose of conducting this method of change detection was not only to estimate the difference of urban land area between 1973 and 2006, but also to highlight areas added to urban landscape from agricultural land and from the adjacent desert separately. In other words, it was important to distinguish pixels which were recorded as agricultural land in 1973 and were added to urban land in 2006 from those which were recorded as desert area in 1973 and were added to urban land in 2006. This process was carried out using the Modeler in ERDAS Imagine. First, each MSS and ETM+ classified image was recoded to have unique ordinal classes. Then the two images were multiplied together to yield a composite image containing the number of pixels converted to urban area either from agricultural land or from desert areas. A "from - to" change matrix [20] was then prepared to extract the separated pixels.

\section{RESULTS AND DISCUSSION}

Accuracy assessment of the classified satellite images reveals a considerable high degree of confidence (Tables

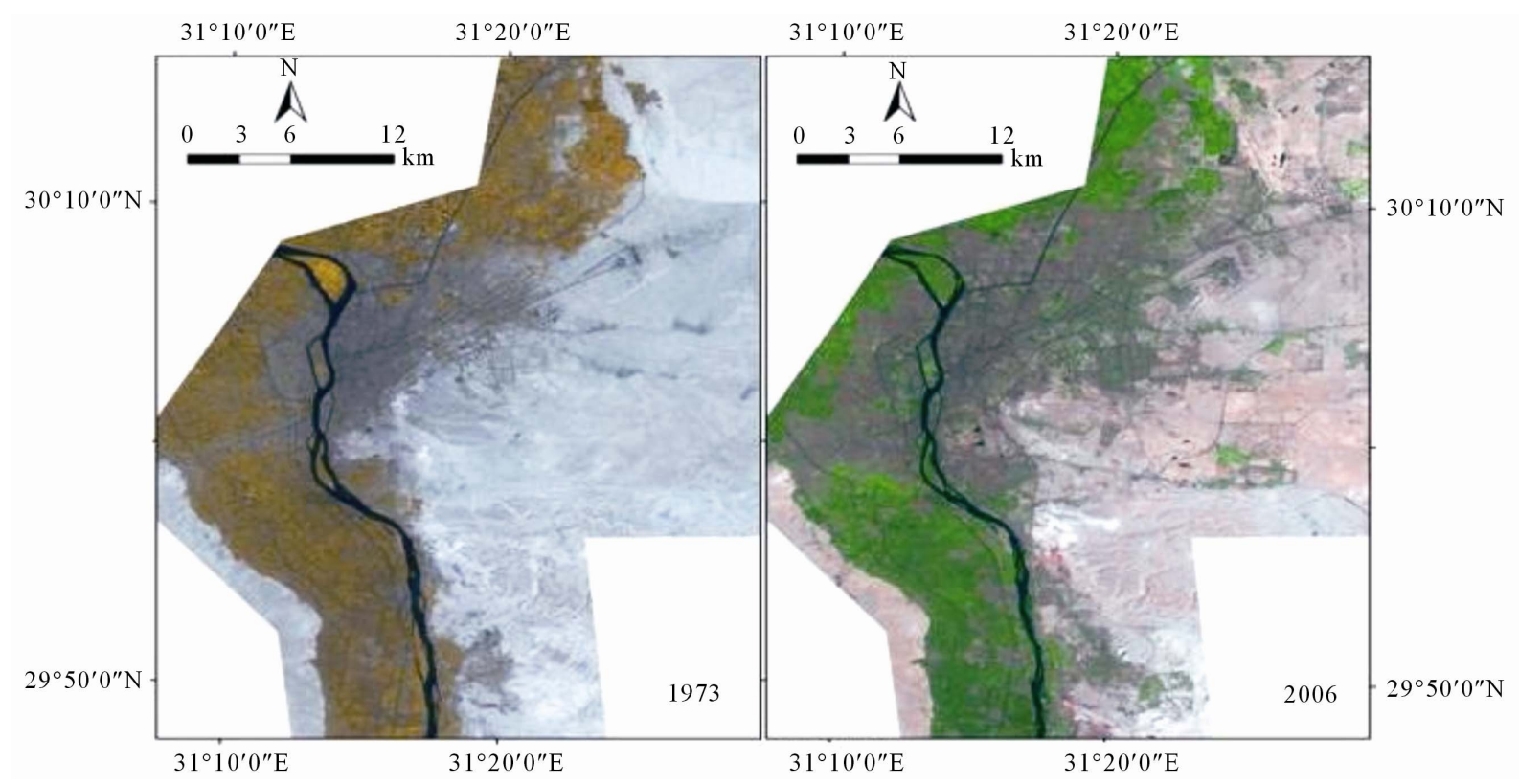

Figure 2. False color composites of the MSS and ETM+ images showing Cairo in 1973 and 2006. 
1 and 2). The overall accuracy of both the 1973 and 2006 land cover maps are $92 \%$ and $86 \%$, respectively, with overall kappa statistics of 0.87 and 0.78 . Producer and user accuracies for individual classes are generally high with maximum producer and user accuracies for water (100\%) in the two land cover maps. The land cover maps resulted from the supervised classification are shown in Figure 3, which shows a tremendous expansion of urban areas toward the north and northeast. Urban areas are estimated at $233.78 \mathrm{~km}^{2}$ in 1973. Between 1973 and 2006, $324.07 \mathrm{~km}^{2}$ of new urban areas have been added to Cairo totaling $557.87 \mathrm{~km}^{2}$ of urban area in 2006. The rate of urbanization was $9.8 \mathrm{~km}^{2} /$ year during the 33 yeas of study (Table 3). This figure $\left(557.87 \mathrm{~km}^{2}\right)$ represents the sum of the original urban land in 1973, the cut-off from contiguous agricultural land around Cairo $\left(136.75 \mathrm{~km}^{2}\right)$, and the newly urbanized desert areas $\left(187.32 \mathrm{~km}^{2}\right)$ between 1973 and 2006. The trade off between the agricultural land, desert, and urban areas are shown in Table 3 and Figure 4. The present study reveals a total increase of urban area from $233.78 \mathrm{~km}^{2}$ to $557.87 \mathrm{~km}^{2}$ with a total increase of $324.07 \mathrm{~km}^{2}$ in 33 years (1973-2006). The present study reveals that urban expansion is observed to be mostly toward north (upon agricultural lands) and toward northeast (desert). The loss of agricultural lands between 1973 to 2006 along the boundaries of Cairo (Figure 4), which totals $136.75 \mathrm{~km}^{2}$ (33,849 acres) represents a significant threat to this non-renewable resource as agricultural land of Egypt is restricted to the
Nile Valley and its delta. Factors driving urban sprawl include demography, regional topography, socio-economic factors and policies.

\subsection{Demography}

The primary driving force for urban sprawl in Cairo is its accelerated population growth, which approached

Table 1. Accuracy assessment matrix for the 1973 land cover map.

\begin{tabular}{cccccc}
\hline & $\begin{array}{c}\text { Producer } \\
\text { Accuracy }\end{array}$ & $\begin{array}{c}\text { User } \\
\text { Accuracy }\end{array}$ & Kappa & $\begin{array}{c}\text { Overall } \\
\text { Accuracy }\end{array}$ & $\begin{array}{c}\text { Overall } \\
\text { Kappa }\end{array}$ \\
\hline Water & 100 & 100 & 1 & & \\
Agriculture & 97 & 97 & 0.95 & 92 & 0.87 \\
Urban & 84 & 84 & 0.80 & & \\
Desert & 93 & 91 & 0.84 & \\
\hline
\end{tabular}

Table 2. Accuracy assessment matrix for the 2006 land cover map.

\begin{tabular}{cccccc}
\hline & $\begin{array}{c}\text { Producer } \\
\text { Accuracy }\end{array}$ & $\begin{array}{c}\text { User } \\
\text { Accuracy }\end{array}$ & Kappa & $\begin{array}{c}\text { Overall } \\
\text { Accuracy }\end{array}$ & $\begin{array}{c}\text { Overall } \\
\text { Kappa }\end{array}$ \\
\hline Water & 100 & 50 & 0.50 & & \\
Agriculture & 95 & 83 & 0.78 & & \\
Urban & 79 & 92 & 0.85 & 86 & 0.78 \\
Desert & 90 & 82 & 0.74 & \\
\hline
\end{tabular}

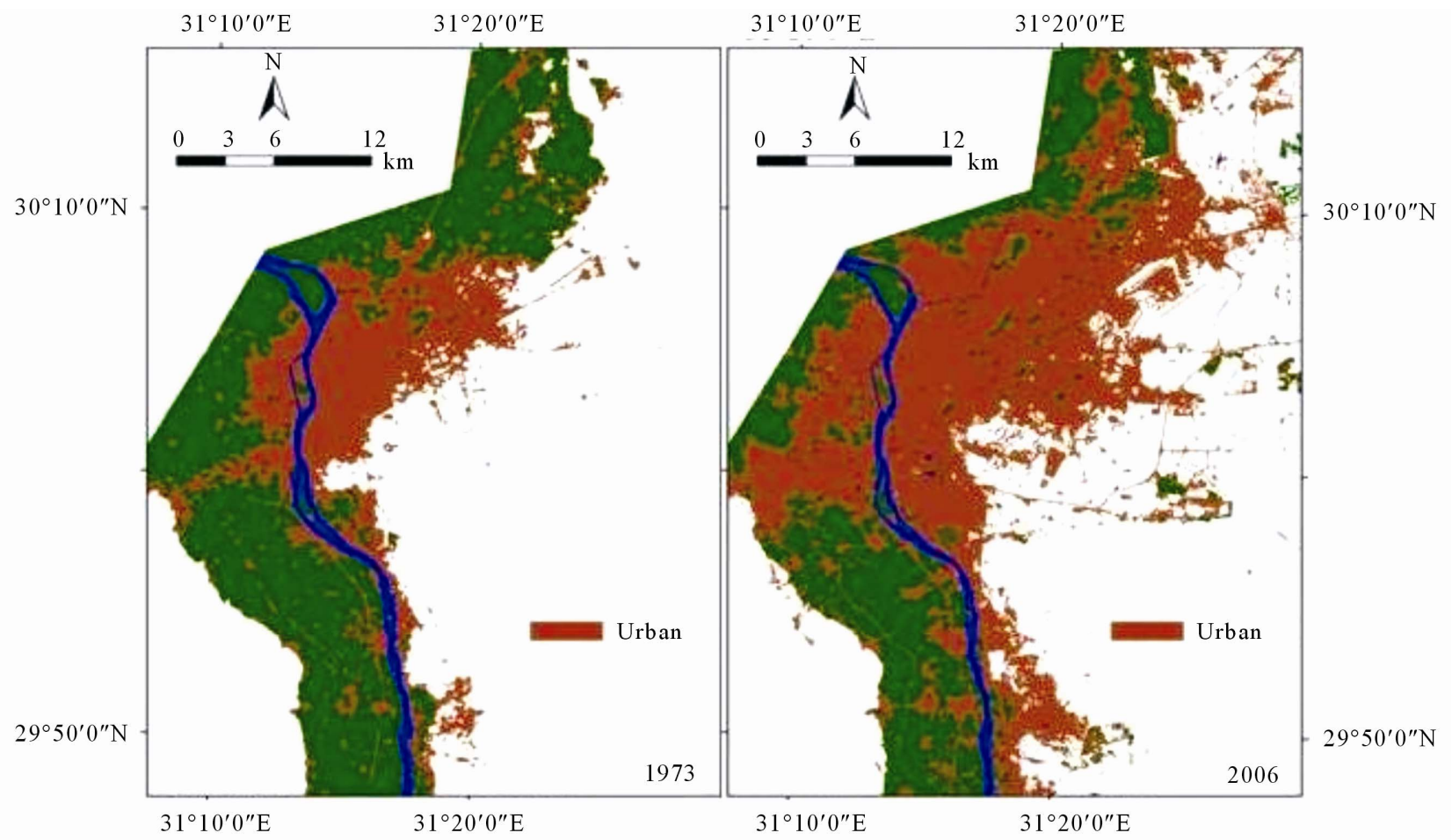

Figure 3. The land cover maps of Cairo in 1973 and 2003. 
Table 3. The change matrix between land cover classes of Cairo. Areas are in $\mathrm{km}^{2}$.

\begin{tabular}{ccccc}
\hline & Water & Agriculture & Urban & Desert \\
\hline Water & 19.92 & 0 & 0 & 0 \\
Agriculture & 0 & 200.09 & 136.75 & 0 \\
Urban & 0 & 0 & 233.78 & 0 \\
Desert & 0 & 0 & 187.32 & 608.85 \\
Total & & & $\mathbf{5 5 7 . 8 7}$ & \\
\hline
\end{tabular}

2.74\% during the period (1976-1986) and 1.6\% for the 1996 census [15]. During the period of the present investigation, about 7 million persons have been added to the population of Cairo. This quick population growth entailed the construction of new urban communities, such as El-Salam, El-Obour and New Cairo settlements. New ring road has been constructed to encompass Cairo. This road was established mostly upon agricultural lands.

\subsection{Regional Topography}

The analysis of the DEM of Cairo area (Figure 5) denotes the occurrence of a wide plain less than $30 \mathrm{~m}$ above sea level, where Cairo exist, and this plain extends to the north and to the northeast forming the Nile Delta. For thousands of years, agricultural lands of the country occur at this plain. The eastern side of this plain is bordered by Al-Mokatam plateau, which rises to more than $150 \mathrm{~m}$ above sea level. This regional topography is the second influencing factor for urban expansion that drove new settlements toward the northern frontiers (upon agricultural land) and the northeastern desert plain. However, some communities were constructed at Al-Mokatam plateau.

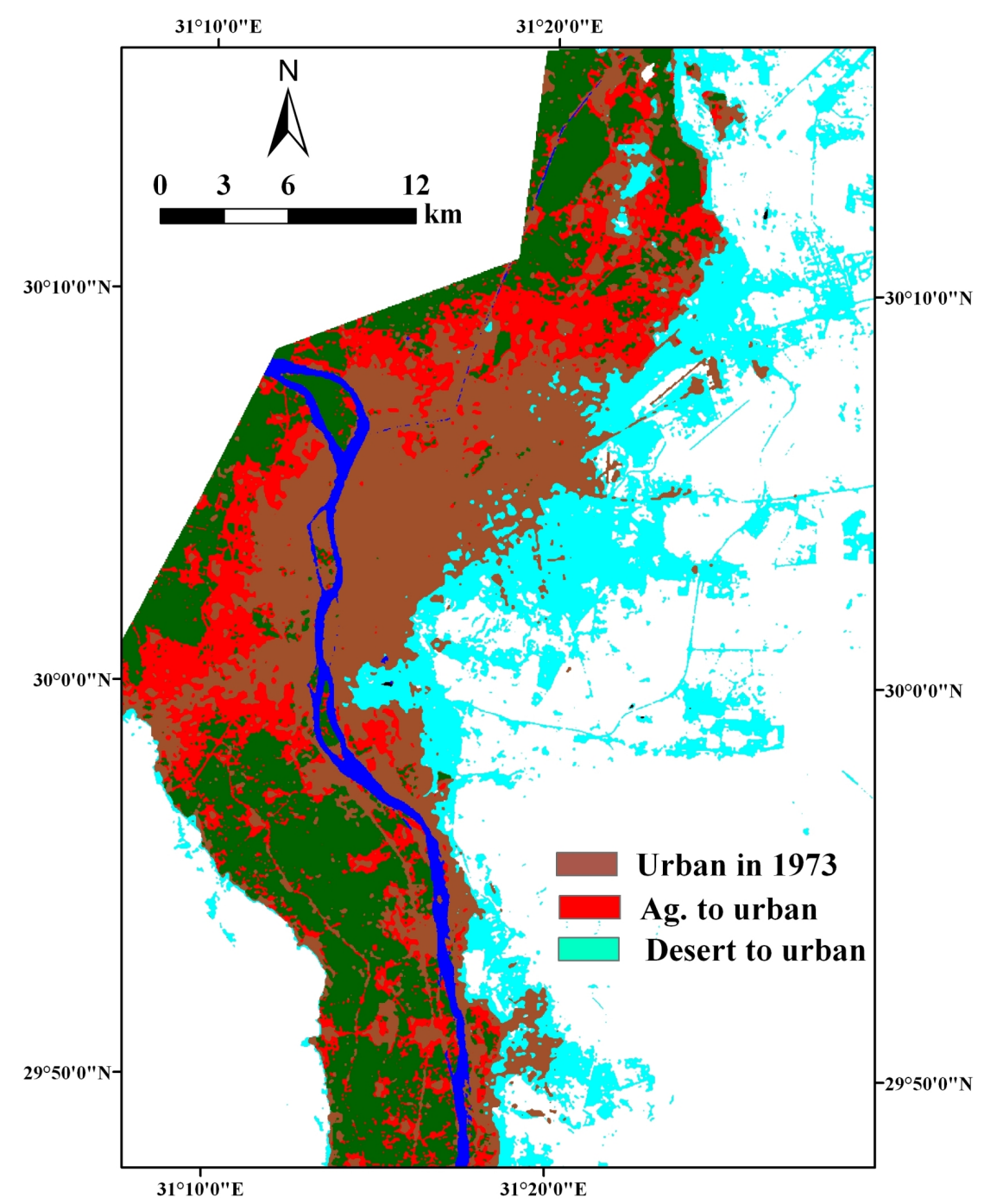

Figure 4. The land cover map of Cairo showing the exchange between agricultural land, bare desert and urban area between 1973 and 2006. 


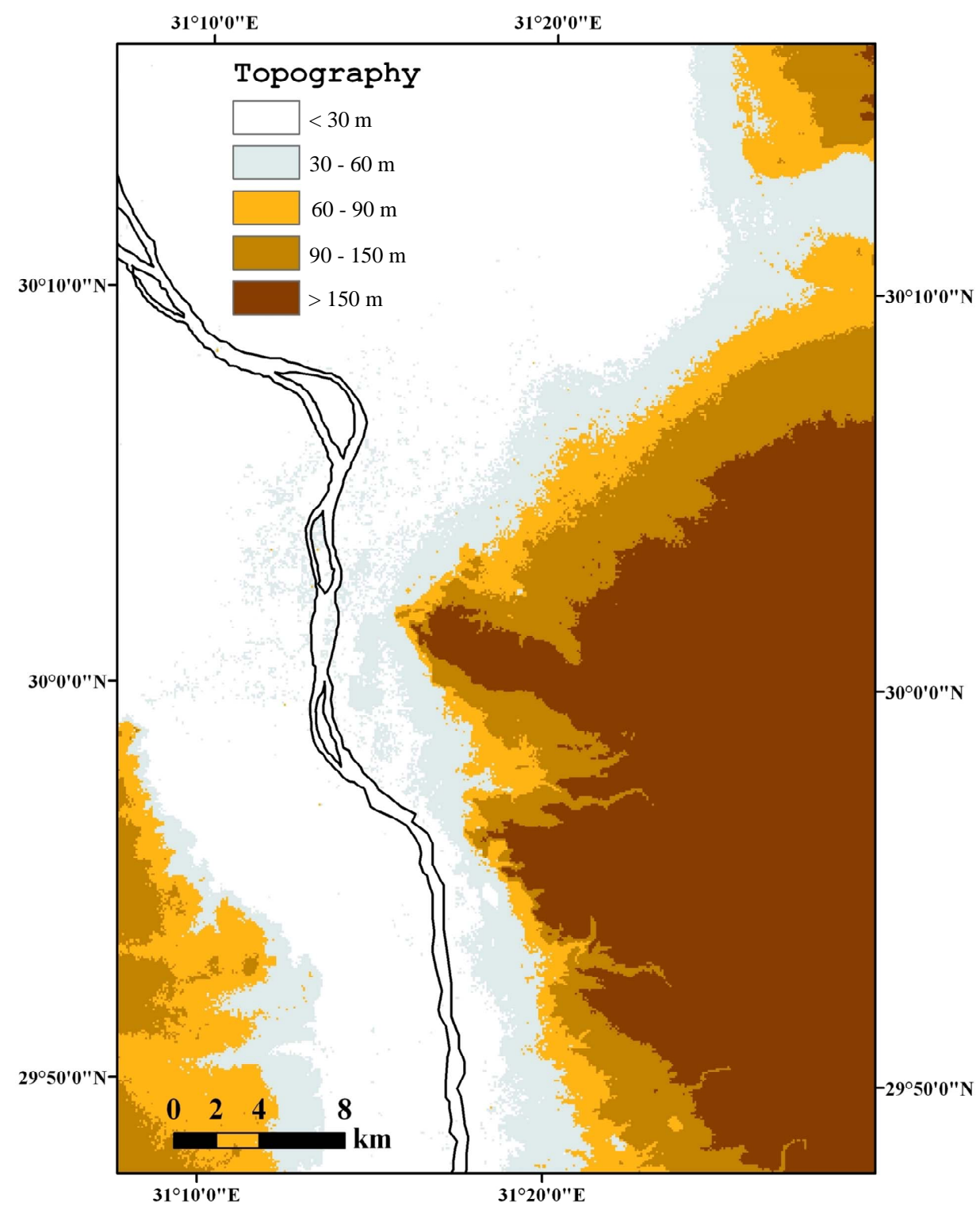

Figure 5. The digital elevation model (DEM) of Cairo region showing the eastern plateau.

\subsection{Socio-Economic Factors}

Most of government facilities occur at Cairo, which is the homeland of the cabinet. At least 2 - 3 million persons from all sides of the country visit Cairo daily for work or for government facilities. Internal migration from rural areas for better living conditions is another influence for urban agglomeration. The leading universities, sports activities, media and major companies headquarters occur in Cairo. Although many new towns have been established far from Cairo to attract people outside the capital, inadequate services and the lack of social and educational infrastructure have also depressed families from settling in the new towns. Moreover, high prices of housing in the new towns are among the reasons discouraging families to live in these new communities.
However, some industrial towns, such as $10^{\text {th }}$ Ramadan and $6^{\text {th }}$ October partially succeeded to attract people for residence.

\subsection{Policies}

Creep upon contiguous land rather than jump outside the capital toward desert was the pattern of urban sprawl in Cairo. Although, there is a law to prohibit building upon productive agricultural land, there were not much deterrent actions against cases of infringement upon productive agricultural lands. Significant urban agglomeration occurred as slums and uncontrolled housing around the capital with poor sanitary and educational infrastructures. In additions, cemeteries were used as homes for millions of homeless people in Cairo. 


\section{CONCLUSION}

Remote sensing is an effective tool to map and analyze urban sprawl and to provide valuable information necessary for planning and development. The primary concern of the present investigation is that continuing urban encroachment northward of Cairo could imply potential threats to agricultural lands. There should be firm and stiff legal actions against any violation upon this nonrenewable resource. There should be more facilities to involve the private sector and to prevent means of monopoly.

\section{REFERENCES}

[1] Iverson, L.R., Cook, E.A. and Graham, R.L. (1989) A technique for extrapolating and validating forest cover across large regions: Calibrating AVHRR data with TM data. International Journal of Remote Sensing, 10, 18051812. doi:10.1080/01431168908904011

[2] El-Baz, F., Breed, C.S., Grolier, M.J. and McUauley, J.F. (1979) Eolian features in the western desert of Egypt and some applications to Mars. Journal of Geophysical Research, 84, 8205-8221. doi:10.1029/JB084iB14p08205

[3] Abdel-Hamid, M.A., Shreshta, D. and Valenzuela, C. (1992) Delineating, mapping and monitoring of soil salinity in the Northern Nile Delta (Egypt) using Landsat data and geographic information system. Egyptian Journal of Soil Science, 32, 463-481.

[4] Frify, O.E., Nasr, S.M., El-Hattab, M.M. and El-Raey, M. (1994) Remote sensing of beach erosion along the rosetta promontory, north-western Nile delta, Egypt. International Journal of Remote Sensing, 15, 1649-1660. doi:10.1080/01431169408954197

[5] Guirguis, S.K., Hassan, H.M., El-Raey, M. and Hussain, M.A. (1996) Multi-temporal change of Lake Burullus, Egypt, from 1983 to 1991. International Journal of Remote Sensing, 17, 2915-2921. doi:10.1080/01431169608949118

[6] Frihy, O.E., Dewidar, K.M., Nasr, S.M. and El-Raey, M.M. (1998) Change detection of the northeastern Nile Delta of Egypt: Shoreline changes, spit evolution, margin changes of Manzala lagoon and its islands. International Journal of Remote Sensing, 19, 1901-1912. doi:10.1080/014311698215054

[7] Lenney, M.P., Woodcock, C.E., Collins, J.B. and Hamdi, H. (1996) The Status of agricultural lands in Egypt: The use of multitemporal NDVI features derived from Landsat TM. Remote Sensing of the Environment, 56, 8-20. doi:10.1016/0034-4257(95)00152-2

[8] El-Asmar, H. and Hereher, M. (2011) Change detection of the coastal zone east of the Nile Delta using remote sens- ing. Environmental Earth Sciences, 62, 769-777. doi:10.1007/s12665-010-0564-9

[9] Hereher, M. (2010) Vulnerability of the Nile Delta to sea level rise: An assessment using remote sensing. Geomatics, Natural Hazards and Risk, 1, 315-321. doi:10.1080/19475705.2010.516912

[10] Masek, J.G., Lindsay, F.E. and Goward, S.N. (2000) Dynamics of urban growth in the Washington DC metropolitan area, 1973-1996, from Landsat observations. International Journal of Remote Sensing, 21, 3473-3486.

[11] Yagoub, M.M. (2004) Monitoring of urban growth of a desert city through remote sensing: Al-Ain, UAE, between 1976 and 2000. International Journal of Remote Sensing, 25, 1063-1076. doi:10.1080/0143116031000156792

[12] Yuan, F., Sawaya K., Loeffelholz, B.C. and Bauer, M. (2005) Land cover classification and change analysis of the Twin Cities (Minnesota) metropolitan area by multitemporal Landsat remote sensing. Remote Sensing of Environment, 98, 317-328. doi:10.1016/j.rse.2005.08.006

[13] Fahim, M.M., El-Khalil, K.I., Hawela, F., Zaki, H.K., El-Mowelhi, M.N. and Lenney, M.P. (1999) Identification of urban expansion onto agricultural lands using satellite remote sensing: Two case studies in Egypt. Geocarto International, 14, 45-47. doi:10.1080/10106049908542092

[14] Yin, Z.Y., Stewart, D.J., Bullard, S. and MacLachlan, J.T. (2005) Changes in urban built-up surface and population distribution patterns during 1986-1999: A case study of Cairo Egypt. Computers, Environment and Urban System, 29, 595-616. doi:10.1016/j.compenvurbsys.2005.01.008

[15] Sutton, K. and Fahmi, F. (2001) Cairo's urban growth and strategic master plans in the light of Egypt's 1996 population census results. Cities, 18, 135-149. doi:10.1016/S0264-2751(01)00006-3

[16] Chavez, P.S. (1996) Image-based atmospheric correction: Revised and improved. Photogrammetric Engineering and Remote Sensing, 62, 1052-1036.

[17] Congalton, R.G. (1991) A review of assessing the accuracy of classification of remotely sensed data. Remote Sensing of Environment, 37, 35-46. doi:10.1016/0034-4257(91)90048-B

[18] Lu, D., Mausel P., Brondiozio, E. and Moran, E. (2004) Change detection techniques. International Journal of Remote Sensing, 25, 2365-2407. doi:10.1080/0143116031000139863

[19] Singh, A. (1989) Digital change detection techniques using remotely sensed data. International Journal of Remote Sensing, 10, 989-1003. doi:10.1080/01431168908903939

[20] Jensen, R.J. (1995) Introductory digital image processing. Prentice Hall, Upper Saddle River. 